(C) ACM, 2017. This is the author's version of the work. It is posted here by permission of ACM for your personal use. Not for redistribution. The definitive version was published in Proceedings of the 29th Australian Conference on Computer-Human Interaction, ISBN: 978-1-4503-5379-3, https://doi.org/10.1145/3152771.3152786

\title{
The Impacts of Deaf Culture on Designing with Deaf Children
}

\author{
Jessica Korte \\ IDEA Lab, Griffith University \\ 170 Kessels Rd, Nathan, Qld \\ Australia \\ j.korte@griffith.edu.au
}

\section{ABSTRACT}

This paper will discuss the impacts Deaf culture and the traits of individual Deafness have on the conduct of co-design with Deaf children. A series of design sessions were undertaken with a design team composed of young Deaf children, the first author as an adult designer, members of an Early Childhood Development Program's staff, and the parents of the young Deaf children. From the interactions of the design team, lessons about the impact of Deaf culture and individual Deafness have been identified. Designers wishing to work with young Deaf children must consider the impacts Deafness and Deaf culture will have on their design activities if they wish to maximise Deaf children's involvement in and contribution to those design activities.

\section{CCS CONCEPTS}

- General and reference Design - Human-centered computing HCI design and evaluation methods • Humancentered computing Participatory design • Human-centered computing User centered design - Social and professional topics Children - Software and its engineering Designing software • Software and its engineering Software prototyping

\section{KEYWORDS}

Design; Deafness; Deaf; Deaf children; Deaf culture; crosscultural design.

\section{ACM Reference format:}

J. Korte, L. E. Potter, S. Nielsen, 2017, The Impacts of Deaf Culture on Designing with Deaf Children. In Proceedings of the 29th Australian Conference on Human-Computer Interaction, Brisbane, QLD, Australia, November 2017 (OzCHI 2017), 8 pages.

https://doi.org/0000001.0000001

\section{INTRODUCTION}

Deaf children (and Deaf adults), as a user group and potential design partners, have unique traits and needs which must be

\footnotetext{
Permission to make digital or hard copies of part or all of this work for personal or classroom use is granted without fee provided that copies are not made or distributed for profit or commercial advantage and that copies bear this notice and the full citation on the first page. Copyrights for third-party components of this work must be honored. For all other uses, contact the owner/author(s).

OzCHI'17, November 2017, Brisbane, Queensland, Australia

(C) 2017 Copyright held by the owner/author(s). xxx-xxxx-xx-xxx/xx/xx. . \$xx.xx DOI: $\mathrm{xx} . \mathrm{xxx} / \mathrm{xxxx} \_\mathrm{x}$
}

\author{
Sue Nielsen \\ IDEA Lab, Griffith University \\ 170 Kessels Rd, Nathan, Qld \\ Australia \\ s.nielsen@griffith.edu.au
}

addressed in the design of both technologies and design approaches [31]. Some of these traits are physiological or psychological, caused by their deafness. However, some of the traits are cultural, as western Deaf societies identify themselves as belonging to Deaf culture, in the same way that people from different ethnicities or countries identify themselves as belonging to particular cultures. Drawing a line between the effects of the physiological or psychological and cultural can be difficult, especially in real-world situations, as Deaf culture is shaped by the abilities and traits of Deaf people.

Research has been undertaken to understand the physiological and psychological traits of deaf and Deaf people (e.g. [3, 4, 10, $28,30,36,38]$ ), and how these impact on designing with Deaf children [22, 31, 33], but little research has examined the implications of Deaf culture on designing with Deaf children.

This paper will identify the impacts of Deaf culture and individual children's Deafness on a series of design sessions undertaken with four young Deaf children. Working with young Deaf children highlighted the communication gap between Deaf and hearing cultures, and provided a situation in which the most extreme accommodations would be necessary. Designers working with older Deaf children or Deaf adults will find that accommodations such as the ones we describe will facilitate communication and ease the conduct of design tasks.

\subsection{Terminology: 'Deaf' vs 'Deaf}

The terms deaf and Deaf will be used according to their cultural definitions amongst the Australian Deaf community. This is consistent with the guidelines provided by Deaf Australia. Lower case deaf is used to describe an individual with some form of hearing loss. Upper case Deaf describes individuals who identify as belonging to the signing Deaf community and who communicate using Auslan (Australian Sign Language).

People who identify as "culturally Deaf" are more likely to have been born deaf or become deaf early in life, are pre-lingually deaf and use sign language as a primary or preferred mode of communication. Deaf people of the western world often identify as a culture with distinct languages and customs, in the same way that people of any particular ethnic group may identify as belonging to that culture [7].

\section{LITERATURE REVIEW}

The importance of designing with, not just for, children has been recognised within the field of human-computer interaction, as children have their own experiences, expertise, and needs which 
adult representatives cannot adequately represent in designing technologies [9].

The term 'special needs' within the Deaf community is used in relation to people who are Deaf and who also have another health issue that impacts their quality of life. However, it appears in references to other researchers' work where deafness is categorised as a 'special need' condition in its own right. Where this occurs, we will use the term as it is used by the original researcher for the purposes of discussion.

Where once it was deemed acceptable to just "ask an adult", thereby gathering proxy information about children, especially young children or children with a special need, it is now recognised that these children have unique ideas, opinions and insights which would be invaluable to the design process $[1,13]$.

Druin identified five roles which children can take when involved in design activities. From least involved to most involved, these are: user, tester, informant, equal design partner [9] and software designer [13]. Historically, children with "special needs" have been included in design activities, but only in lessinvolved roles such as user or tester, with adults creating for them, rather than with them. To address this, Guha, Druin, and Fails' Inclusionary Model for designing with children with "special needs” provides a framework for supporting children's needs in such a way that any child may take any design role if provided with sufficient support [14]. To address the needs of Deaf children, the Inclusionary Model recommends the inclusion of a sign language interpreter [14], but this recommendation overlooks the cultural aspects of Deafness. The authors of this paper have also been guilty of overlooking this aspect of design in their past work [23, 24, 32]. Designing with Deaf people involves designing across a language and cultural gap.

\subsection{The Effects of Children's Individual Deafness}

Research literature has recognised that Deaf children have particular traits which should be considered when co-designing with them. These studies examine the traits of Deaf or deaf children, and how these impact on the conduct of design sessions.

$70-95 \%$ of deaf children are born to hearing parents [6, 12]. It has been shown that deaf children born to hearing parents are slower to acquire language, which leads to ongoing learning [27], behavioural and attention difficulties [3, 30, 31]; reduced literacy [29, 34, 38] and language skills [28]; lower academic performance in a range of subjects [36]; and lower social and emotional development [4, 34] compared to hearing children or the children of Deaf parents.

Deaf people tend to be strongly visual [31]. They are known to use visual-spatial cognitive processing [10], and have more sensitive peripheral vision than hearing people [16, 30].

The greatest difficulties encountered in designing with Deaf children are caused by the language barrier or the communication gap [31]. Working across languages should involve active awareness on the part of the researcher that interpretation cannot be one-to-one [37]. Young children with delayed language acquisition and low language skills need more communication support than interpretation; this is supported by the fact that Deaf and deaf children can be active and creative in attempting to communicate when they lack skills in signed and spoken languages [40].

\subsection{Deaf Culture as a Whole}

The Australian Deaf community is a distinct, minority subculture within the wider Australian community. Signing, sport, and cultural involvement through gatherings, conferences, festivals and clubs have been identified as values within Australian Deaf culture [20].

Johnston and Schembri [20] describe the use of sign language as a defining characteristic of Deaf culture. In Australia, the use of Auslan is an indicator of Deaf identity, although not necessarily membership of the Deaf community, which requires involvement with other members of the Deaf community. Physical deafness does not necessarily correlate with a Deaf identity, as the children of Deaf adults are often raised with Auslan as a first language, and are members of the Deaf community; conversely, some deaf people, whether or not they sign, never join the Deaf community [20]. This is due to the fact that cultural membership is not passed from (hearing) parents to (deaf) children, as is the case in other minority subcultures. Instead, membership of the Deaf community must be deliberately sought by parents (on behalf of their children) or the children themselves as they age [18, 20].

Communication within Deaf culture, being primarily signed, has different cues from communication in hearing culture. Initiating communication requires that visual attention be gained. Common techniques include waving within a person's field of vision, lightly touching their arm or shoulder, or tapping or stamping a surface to cause vibrations [20]. Visual attention must then be maintained throughout the communication [39].

Body language and facial expression, often identified as nonverbal aspects of communication among the hearing community, are integral to Auslan communication [35], as posture and expression can change the meanings of signed communication [20], and can be used to convey intensity or gravity [39].

\subsection{Culture in Human-Computer Interaction}

The relevance of considering different cultures in humancomputer interaction has been recognised since 1975 (Honold in [5]), and had progressed through different periods of focus [5].

Clemmensen and Roese recognise culture as being influenced by "country boundaries, language, cultural conventions, race and religious" differences [5]. As described in Section 2.2 above, Australian Deaf culture is identified by country boundaries, language and cultural conventions. As the authors of this study are also Australian, the overall focus of this research is on the language and cultural conventions of Deaf culture, especially as they apply to communication. This aligns with Saville-Troike's description that "the essential criterion for 'community' is that some significant dimension of experience be shared, and for 'speech community' that the shared dimension be related to ways in which members of the group use, value, or interpret language” [35]. Insufficient consideration being given to cultural differences, 
including aspects of communication, is a major source of problems in cross-cultural design [5].

\subsection{Examples of Cross-Cultural Design with Children}

There has been some research conducted on designing with children across a cultural gap created by researchers from one country designing with children from another country [2, 15, 21].

Kam, Ramachandran, Raghavan, Chiu, Sahni and Canny, as researchers from USA and India (and from a range of ethnicities, including Chinese and Indian [21]) designing with rural Indian children, discussed and examined the cultural causes of difficulty in designing across cultures [21]. Relative exposure to technology, educational approaches, cultural values and power differentials (between adults and children, and between cultures) were all identified as influencing factors on design activities. These researchers involved child and adult members of the "target" culture as interpreters and facilitators of the design sessions undertaken. They found that the involvement of native adult facilitators helped the progress of the sessions in multiple ways, including through elucidating cultural norms and attitudes. Locally available materials were used in the design sessions. Exchanges of languages and cultures were used as icebreaking activities, to build a relationship between adult and child designers.

Antle and Bevans, as Canadian researchers designing with and for urban Nepalese children, incorporated cultural awareness activities into their design workshops [2]. These authors acknowledged that the already-recognised power differentials between adults and children could be exacerbated by the cultural gap.

Hamidi, Saenz and Baljko considered the implications of the children's social and cultural context in their Sparkles of Brilliance project, which involved researchers from Canada and Mexico working with children from Mexico [15]. The children involved had a low level of access to and familiarity with technology, due to the children's national culture and socioeconomic background. Locally available materials were used in the design sessions. Cultural awareness activities, particularly around the art of the children's culture, were incorporated as part of the design sessions.

These examples show that cultural factors, including language, power differentials, cultural values, educational approaches and level of technology exposure, should be considered when designing with children whose cultural backgrounds differ from those of the adult designers.

\section{DESIGNING WITH YOUNG DEAF CHILDREN: OUR EXPERIENCES}

A series of 25 30-minute design sessions were conducted across 35 weeks with four young (3-5 years old) Deaf children of hearing parents, attending an Education Queensland Early Childhood Development Program (ECDP). These were conducted as part of a larger research project exploring co-design with young Deaf children [26]. All design sessions were attended in part by a Deaf Auslan Language Model (ALM) or a hearing Educational Interpreter (EI) employed by the ECDP. Some parents of the children attended parts of the design sessions. The first design session was attended by a professional Auslan interpreter.

The children involved in this study will be referred to as PARTICIPANT E (female, 4 years old at the commencement of the study), PARTICIPANT D (female, 4.5 years old at the commencement of the study, PARTICIPANT S (female, 3.5 years old at the commencement of the study) and PARTICIPANT SH (male, 3 years 8 months when he joined the study, 9 weeks after the initial commencement).

The design sessions aimed to explore different potential techniques that could be used for co-design with children who are Deaf, and were intentionally modelled on the "bags of stuff" technique from the Cooperative Inquiry method for designing with children [8, 11, 13]. A collection of expressive materials, such as stickers, modelling clay, chenille sticks and balloons, were provided as the medium for the design team of adults and children to explore topics of interest. In early design sessions, specific goals were intended for design activities, such as the design of communication aids for young Deaf children. However, we found that it was difficult to communicate such specific aims, as the children lacked the ability and interest in abstract communication required to communicate tasks such as "create images to represent happiness and sadness”. It was more productive to attempt to explore general themes with the children, and communicate the themes through the choice of expressive materials provided, and/or through demonstrations. For example, in one design session, the general theme was "characters". Adult design team members demonstrated the topic by creating physical characters out of expressive materials, including balloons, chenille sticks, facial feature stickers and cardboard tubes. PARTICIPANT E engaged with the creations, critiquing the balloon-headed person created by the first author, and adopting and iterating on the cardboard tube person created by the ALM.

\subsection{Data and Analysis}

In all design sessions, research data was collected by a note-taking observer. Video data was collected in some design sessions. Immediately after each design session, the first author and the observer conducted a reflective debrief of the session, drawing on their memories of the design session activities to provide details to accompany the observer's notes. This also acted as an initial round of data analysis, as initial behaviour patterns, including successes achieved and challenges encountered, emerged during the reflective debrief. Particular attention was paid to difficulties encountered during the sessions, as these indicated areas which required alteration to accommodate the needs of young Deaf children. During evaluation of the design sessions, video records (when available) were used to verify the timing and sequence of events from the design sessions, and at times to provide more details about particular events. Video data was not transcribed.

Analysis of the data involved identifying key instances of communication and design activities within the design sessions. 
These were catalogued according to a conceptual framework of design principles and goals drawn from the research literature on designing with children, and evaluated for efficacy and effectiveness according to the principles and goals. Likely causes and influencing factors, including the children's youth and Deafness, were identified. That analysis formed the basis of the first author's $\mathrm{PhD}$ thesis [26]. This paper draws off the identification of the children's Deafness and deafness as likely causes of instances within the design sessions to enable discussion of the impacts of Deaf culture on the design sessions.

\section{THE IMPACTS OF DEAFNESS AND DEAF CULTURE ON DESIGNING WITH CHILDREN}

We found that the conduct of the design sessions was strongly influenced by both Deaf culture and the children's individual Deafness and deafness. The youth of the children and their early stage of language acquisition also had an impact on the way Deaf culture interacted with the design session activities and format. The following sections will discuss the aspects of the design sessions which were most influenced by the children's Deafness and Deaf culture generally, and the ways in which the design sessions were adapted to address them.

\subsection{Designers Familiarising Themselves with Children's Culture}

Before the design sessions began, the first author attended Auslan classes and social events hosted by local Deaf organisations to become familiar with Australian Deaf culture. This had several advantages throughout the design sessions, with lessons about Deaf culture, etiquette and customs impacting interactions with both the Deaf children and the Deaf adult staff of the ECDP. Further immersion in Deaf culture could have made interactions even smoother, as some aspects of Deaf culture, including cultural norms for communicating with young Deaf children, such as signing into their line of sight when they would not give their visual attention, were difficult to enact in early design sessions due to the first author's lack of familiarity with those cultural customs.

\subsection{Communication Cues from Deaf Culture}

There were several cues observed in communications within the design sessions which seem to be related to Deaf culture and customs.

As described in the Literature Review section above, to attract attention in Deaf culture, it is appropriate to lightly touch someone's arm if you are close to them, or to wave if you are outside of touching distance. It is then necessary to wait until they turn their visual attention to you before you can begin to communicate. If you lose visual attention (that is, if the person you are communicating with looks away from you), it is important that you either wait for, or attempt to attract in the ways described above, their attention again before continuing to communicate. As a hearing person, this can be a surprisingly difficult adjustment to make. Young Deaf children switched their attention away from signed communication with much greater frequency than adults. Deaf adults, as fluent signers and natives of the Deaf community, were much better at attracting and retaining young Deaf children's visual attention, and communicating with them. They would locate themselves within the design session room in such a way to allow for clear lines of sight between them and the children, supporting visual communication. They would use communication-getting cues, such as waving or gentle taps on the arm, to get attention. They would wait patiently for the full attention of the person they wished to communicate with, and were sensitive to distractions, and would move and/or repeat their signing as required for the person they were communicating with to see the signs and understand the message. Deaf adults were skilled at keeping the children's visual attention, through the use of signs, facial expressions, playfulness, repetition, and situational tools - for example, linking the signing of colours to children's choice of materials. This behaviour has similarities to the way Deaf parents communicate with their infant children, using attention-getting behaviours to communicate, teach signs, and to guide children's attention [17, 27], although it is much broader in scope.

Within the ECDP, a signal which is used to communicate is the flashing of room lights to indicate the end of an activity or time period. This replaces the use of bells which is common in schools attended by hearing children, and is a common signal within the Deaf community for formal group events [20]. This signal was adopted within our design session as a familiar way of communicating a specific message.

The young Deaf children used pointing gestures in a way which was closer to pointing in Auslan than the way a hearing person would use pointing. They pointed to people and particular materials as a way of directing attention or requesting materials. This has some similarities to the way signing is used in Auslan, to specify referents which are present and visible [19]. Such pointing was usually paired with other non-verbal signals, such as expressions, which made children's intentions clear. To use the example of the balloon-headed character discussed previously, PARTICIPANT E's critiquing style involved pointing to various aspects of the character and indicating her reaction through her facial expressions and wordless vocalisations. For example, when it was first created and shown to her, the chenille stick legs were of different lengths. PARTICIPANT E pointed to the shorter leg with a gasp and a horrified expression.

In interactions between Deaf and hearing people, Deaf people can fall back on what is known as the "Deaf nod". This is the situation in which Deaf people nod when they have missed information, but don't want to ask someone to repeat themselves. The child participants used this several times in the design sessions, in response to signed and spoken communication which they did not understand.

\subsection{Interpreters or Support Assistants}

Interpretation during the design sessions was conducted at various points throughout the design sessions by different members of the 
ECDP staff (a Deaf ALM or a hearing EI), a professional interpreter who had previously been contracted by the ECDP (in only one design session), and/or by the parents of some of the young Deaf children attending the design sessions, on an asneeded basis.

In the case of the ALM, the professional interpreter, and the children's parents, the "interpreters" behaved more like "support assistants", as described by Allsop and colleagues [1]. They did not merely interpret; they also prompted the children to participate in the design sessions, guided design session activities, questioned the children to elicit information about their thought processes, trained children to use unfamiliar expressive materials, and provided Auslan lessons to children and the first author during the design sessions.

It is particularly interesting to note that, despite being hearing and knowing varying levels of Auslan and English, children's parents who spontaneously took on a "support assistant” role were supportive of their children's attempts to communicate, especially signed communication, and their children's choices of activities within the design sessions. Involving parents in design sessions with their children has not previously been examined in the research literature (likely due to the power imbalance between parents and their children, caused by the perception that adults have knowledge and expertise which children lack due to their youth [9]), except where parents and carers act as proxies for the children. We theorise that the parents' limited knowledge of Auslan was actually helpful in promoting the respect seen between children and their parents within our design sessions. It brought the adults' self-perceived expertise (of Auslan) more in line with the children's. Another contributing factor in this case may be cultural: these hearing parents have chosen to embrace their children's flourishing Deaf identities, and support activities which enhance this, while recognising their outsider status in Deaf culture - again, this lowers their self-perceived expertise (of Deafness and Deaf culture).

Within the design sessions, adults in "support assistant" roles also acted as members of the design team, offering their insights and contributing to design session activities.

\subsection{Heightened Awareness of Non-Verbal Communication}

The children involved in the design sessions undertaken were young enough that they were not fluent in any language, although they were learning Auslan through the ECDP, and their parents reported that they were (also) learning English, Arabic and/or Dari. This meant that the majority of communication within the design sessions occurred non-verbally. Some of these non-verbal communication cues were different in nature and intensity compared to non-verbal communication behaviours shown by hearing children.

Intentional communication from the children who were Deaf included wordless vocalisations intended to attract attention or convey emotions, and responding to adults' verbal communications through their expressions and actions.
In addition to intentional non-verbal communication, adults who paid attention to children's behaviour could gain information about children's opinions and thought processes which the children were not intentionally communicating. Children's nonverbal actions which conveyed information included: shifting attention; facial expressions and body language; hesitation; and disengaging from activities which were not of interest. Such actions could indicate children's interest in topics and materials, and desired activities.

Being aware of children's intentional and unintentional nonverbal communication allowed adult design team members to better understand children's motivations and thought processes, and to respond quickly to the children's needs. This was highly important when working with young Deaf children who were not fluent in Auslan, and would likely also apply to communicating with older Deaf children. This consideration is important for hearing designers working with Deaf children of any age, as aspects of communication which hearing people consider nonverbal, such as facial expression and body posture, are integral parts of verbal sign language communication.

In addition, Deaf children, likely due to the importance of socalled "non-verbal" communication within sign language, are aware of and respond to adults' intentional and unintentional nonverbal communication. This suggests a cultural aspect to the importance of non-verbal communication in designing with Deaf children.

Of particular interest is the fact that the children were aware of the necessity for visual attention during communication. They would alter and repeat their communicative behaviours based on whether or not the adult/s they were communicating with were paying attention to them.

\subsection{Infeasibility of Conversations}

Many design methods for designing with children rely on discussions and conversations for conveying information, planning, collaborating, and coming to decisions. Due to the youth and low language proficiency of the young Deaf children involved in this research, discussions or conversations were completely infeasible. The children were non-verbal in their communication, as discussed previously. Adult design team members would sign and speak to young Deaf children, attempting to initiate conversations, but the children lacked the abstract language to do so. The children would often pay attention to signing directed at them, especially if it was relevant to the materials and activities they were undertaking, but rarely signed back. It was more common for them to respond in the non-verbal manners described above.

This did not mean that they did not communicate at all. As observed in the research literature [40], the children were creative about communicating when they had something that they considered important to communicate. They would sign at times, usually to request specific materials or creations within the design sessions. When working with adults, or critiquing the creations of others, they would communicate through sign, mime, or nonverbal communications to express their original ideas or 
suggestions for improvements. They could also non-verbally request assistance with tools or materials. In this way, collaboration between adult and child design team members was possible.

This illustrates the importance of finding ways to adjust for and accommodate children's preferred communication styles, especially when those styles are not the norm for hearing designers. Without recognition of the children's communication, important design information would have been lost. Earlier research has identified that flexibility of communication and having multiple channels of communication are important when designing with older Deaf children [31].

\subsection{Communicating Design Session Aims}

Due to the infeasibility of conversations, as discussed above, it was difficult to communicate design session aims to the children. It was impossible to discuss with children the purpose of the design sessions, or to train them in "being designers" [11], as is recommended in the literature. New approaches were required to communicate with the children.

\subsubsection{Problem Demonstration}

Young Deaf children responded positively to demonstrations, both of possibilities and of problems to solve. To illustrate, we will provide two examples.

One demonstration of a problem to solve involved demonstrating the difficulty of trying to blow up a balloon through a straw. This was demonstrated to two participants, PARTICIPANT SH and PARTICIPANT E. PARTICIPANT SH was initially uninterested. PARTICIPANT E was intrigued, and attempted to mimic the first author - a common behaviour in young Deaf children. The ALM pointed out the balloon, and explained in Auslan to PARTICIPANT E that the balloon wasn't sealed. She instructed PARTICIPANT E to wrap the end of the balloon in tape, to seal it. PARTICIPANT E reached for the tape. She was offered chenille sticks, instead, but she shook her head, which seems to indicate that she understood the ALM's lesson. The ALM and PARTICIPANT E taped the balloon to the straw, and PARTICIPANT E was then able to use the straw to blow up the balloon.

PARTICIPANT SH, later in the same session, became interested in the balloons-on-straws which had been created, and attempted to create his own, seeking assistance when he had difficulty. This is an example of a young Deaf child being motivated to creativity by an example of a possibility.

\subsubsection{Implicit Tasks}

Depending on the design session aims, some tasks can be communicated or suggested through the provision of appropriate materials. For example, cardboard mask shapes were provided in one design session. Adult and child participants spent that design session creating masks for themselves, some of which prompted role playing. This is a rather blatant example of implying tasks through materials, but more subtle versions are also possible. In design sessions which intended to explore representations of emotions, multiple sets of stickers were available, including a set of facial feature stickers. Some, but not all, of the children used these stickers to create faces with a wide range of expressions.

\subsubsection{Small Design Teams Support Communication}

The children preferred working individually, or with adult assistance, which may be due more to their youth than their Deafness [11]. However, we found that smaller design teams made communication easier and more likely. It took some time to overcome the children's initial anxiety about involvement in the design sessions [25], and to build sufficient trust between all regular members of the design team. Once the trust had been built, the children were most communicative during one-on-one periods, where the only design team members present were the first author and a single child. This may have been motivated by the children's need and willingness to seek adult assistance, which prompted them to initiate communications. Having fewer people present in the room may have also been a factor, allowing both the child and the first author to focus on each other's communication, without the peripheral distractions of other design team members.

\subsubsection{Sources of "Distractions"}

The greatest source of distractions to design team members were other people. The children, in particular, were prone to noticing other design team members' activities, with all child team members prone to watching the behaviour of other design team members. While this was a distraction from their activities, it was not necessarily a negative, as a great deal of iteration within the design sessions came from children copying or adopting the creations of other design team members and altering them. The children also learned through watching other design team members, and a great deal of the training provided by adults involved either miming or demonstrating the potential uses of particular expressive materials. It is unclear whether this visual focus is due to Deaf children's visual-spatial cognition, the focus of Deaf culture on visual language and learning, or a combination of both.

Children were also readily distracted by people seen through doors and/or windows outside the design session room. Again, this wasn't always negative, as the participants who tended to be most distracted by people outside the design session room (PARTICIPANT E and PARTICIPANT D) also had the habit of taking their creations out of the design session room to "show off" to the adults they had seen outside the room. This indicates a certain amount of pride in and sense of ownership over their creations.

Noises were inconsistently distracting to young Deaf children. Sometimes noises would disturb the children, distracting them from their activities. At other times, the noises were unheard, unnoticed, or ignored.

\section{CONCLUSION}

Within this paper we have argued that awareness of the impacts of cultural Deafness and individual deafness is insufficient for addressing the needs of Deaf people in design activities or 
technologies. A holistic approach is required, due to the interlinked nature of deafness, Deafness and Deaf culture in shaping the ways Deaf people think and behave. We therefore present lessons drawn from our research which highlight how Deaf culture and individual Deafness impacted on the conduct of design sessions with young Deaf children. Some of these impacts required changes and accommodations to the design sessions.

Familiarisation with the local Deaf community was important, but not in itself sufficient to meet the needs of the young Deaf children within the design sessions. Communicating with young Deaf children who have a low level of language acquisition requires greater accommodation than communicating with fluent signers; however, the lessons which can be taken from our design sessions would support and enhance communication with fluent signers. Deaf adult members of the design team demonstrated aspects of this communication, such as the need to attract and retain visual attention during signed communication. Such considerations impacted on the way the design session room had to be arranged - in such a way as to allow clear lines of visual communication - and the use of non-verbal cues in adults' communications to the children. Situational signals, such as the flashing of room lights to indicate the end of a session, were adopted from the standard communication patterns of Deaf culture.

Deaf culture and exposure to sign language impacted the way the children behaved, learned and communicated. As visual thinkers, they tended to learn by watching, and would learn from adult and child members of the design team. They were also alert to the visual attention and non-verbal communication of other design team members, which impacted their approaches to communicating.

Deaf children's communication was almost never verbal, which made conversations or discussions relying on abstract communication infeasible during the design sessions. "Hands on", experiential communication became key, especially for communicating design session aims and activities. For this reason, we developed two new approaches to communicating design session aims, problem demonstration and implicit tasks.

In conclusion, the lessons we have learned about designing with young Deaf children show that it is vitally important to incorporate Deaf culture - the children's culture - into our design sessions, in order to maximise the children's abilities to communicate and contribute as members of the design team.

\section{REFERENCES}

[1] Allsop, M. et al. 2011. Involving children in the development of assistive technology devices. Disability and Rehabilitation: Assistive Technology. 6, 2 (2011), 148-156. DOI:https://doi.org/10.3109/17483107.2010.510178.

[2] Antle, A.N. and Bevans, A. 2012. Creative design: Exploring value propositions with urban Nepalese children. Advances in Computer Entertainment (Kathmandu, Nepal, 2012), 465-468.

[3] Barker, D.H. et al. 2009. Predicting behavior problems in deaf and hearing children: The influences of language, attention, and parent-child communication. Development and Psychopathology. 21, 2 (2009), 373-392.

[4] Calderon, R. and Greenberg, M.T. 2003. Social and emotional development of Deaf children: Family, school, and program effects. Oxford Handbook of Deaf Studies, Language and Education. M. Marschark and P.E. Spencer, eds. Oxford University Press. 177-189.

[5] Clemmensen, T. 2006. Whatever happened to the psychology of human-computer interaction?: A biography of the life of a psychological framework within a HCI journal. Information Technology \& People. 19, 2 (2006), 121-151. DOI:https://doi.org/10.1108/09593840610673793.

[6] Deaf Children Australia and Deaf Services Queensland 2008. Annual Review 2007/2008.

[7] Deaf Culture: http://www.deafculturecentre.ca/Public/Default.aspx?I= 294. Accessed: 2017-02-01.

[8] Druin, A. 1999. Cooperative Inquiry: Developing new technologies for children with children. Proceedings of ACM CHI 99 Conference on Human Factors in Computing Systems (Pittsburgh, PA, USA, 1999), 223230.

[9] Druin, A. 2002. The role of children in the design of new technology. Behaviour and Information Technology. 21, 1 (2002), 1-25. DOI:https://doi.org/10.1080/0144929011010865.

[10] Ebrahim, F. 2006. Comparing creative thinking abilities and reasoning ability of Deaf and hearing Children. Roeper Review. 28, 3 (2006), 140.

[11] Farber, A. et al. 2002. How young can our design partners be? Proceedings of the 2002 Participatory Design Conference (Malmö, Sweden, 2002), 127-131.

[12] Gallaudet Research Institute 2011. Regional and National Summary Report of Data from the 2009-10 Annual Survey of Deaf and Hard of Hearing Children and Youth.

[13] Guha, M.L. et al. 2013. Cooperative Inquiry revisited: Reflections of the past and guidelines for the future of intergenerational co-design. International Journal of Child-Computer Interaction. 1, 1 (2013), 14-23. DOI:https://doi.org/10.1016/j.ijcci.2012.08.003.

[14] Guha, M.L. et al. 2008. Designing with and for children with special needs: An inclusionary model. Proceedings of the 7th International Conference on Interaction Design and Children (2008), 61-64.

[15] Hamidi, F. et al. 2014. Sparkles of brilliance: Incorporating cultural and social context in co-design of digital artworks. Proceedings of the 2014 Interaction Design and Children conference (2014), 77-84.

[16] Hirshorn, E. 2011. Visual Language and Visual Learning (Research Brief 3). Science of Learning Center.

[17] Holzrichter, A.S. and Meier, R.P. 2000. Child-directed signing in American Sign Language. Language Acquisition by Eye. C. Chamberlain et al., eds. Lawrence Erlbaum Associates. 25-40.

[18] Hyde, M. and Punch, R. 2011. The modes of communication used by children with cochlear implants and role of sign in their lives. American Annals of the Deaf. 155, 5 (2011), 535-550. 
[19] Johnston, T. 2013. Auslan Corpus Annotation Guidelines. Macquarie University.

[20] Johnston, T. and Schembri, A. 2007. Australian Sign Language (Auslan): An Introduction to Sign Language Linguistics. Cambridge University Press.

[21] Kam, M. et al. 2006. Practical Considerations for Participatory Design with Rural School Children in Underdeveloped Regions: Early Reflections from the Field. Interaction Design and Children (2006), 25-32.

[22] Korte, J. et al. 2015. An experience in requirements prototyping with young Deaf children. Journal of Usability Studies. 10, 4 (2015), 195-214.

[23] Korte, J. et al. 2012. Designing a mobile video game to teach preliterate Deaf children Australian Sign Language (Auslan). Proceedings of British Computer Society Conference on Human-Computer Interaction (Birmingham, UK, 2012), 345-350.

[24] Korte, J. et al. 2014. Great expectations: What do children expect from their technology? Proceedings of ACM Computers and People Research (Singapore, 2014), 105-111.

[25] Korte, J. et al. 2017. How design involvement impacts Deaf Children. 5th International Conference on Research and Innovation in Information Systems (Langkawi, Malaysia, 2017).

[26] Korte, J. 2017. YoungDeafDesign: A method for designing with young Deaf children. Griffith University.

[27] Masataka, N. 2000. The role of modality and input in the earliest stage of language acquisition: Studies of Japanese Sign Language. Language Acquisition by Eye. C. Chamberlain et al., eds. Lawrence Erlbaum Associates. 3-24.

[28] Mayberry, R. 2010. Early Language Acquisition and Adult Language Ability: What Sign Language Reveals About the Critical. The Oxford handbook of deaf studies, language, and education. M. Marschark and P. Spencer, eds. 281-291.

[29] Mayer, C. 2007. What Really Matters in the Early Literacy Development of Deaf Children. Journal of Deaf Studies and Deaf Education. (2007). DOI:https://doi.org/10.1093/deafed/enm020.

[30] Mitchell, T. V. and Quittner, A.L. 1996. Multimethod study of attention and behaviour problems in hearingimpaired children. Journal of Clinical Child Psychology. 25, 1 (1996), 83-96.

[31] Potter, L.E. et al. 2014. Design with the Deaf: Do Deaf children need their own approach when designing technology? Proceedings of the 2014 Interaction Design and Children conference (Aarhus, Denmark, Jun. 2014), 249-252.

[32] Potter, L.E. et al. 2011. Seek and Sign: An early experience of the joys and challenges of software design with young Deaf children. Proceedings of the 23rd Australian Computer-Human Interaction Conference (Canberra, Australia, 2011), 257-260.

[33] Potter, L.E. et al. 2012. Sign My World: Lessons learned from prototyping sessions with young Deaf children. Proceedings of the 24th Australian Computer-Human Interaction Conference (Melbourne, Australia, Nov. 2012), 501-504.
[34] Sass-Lehrer, M. and Bodner-Johnson, B. 2003. Early intervention: Current approaches to family-centred programming. Oxford Handbook of Deaf Studies, Language and Education. M. Marschark and P.E. Spencer, eds. Oxford University Press. 65-81.

[35] Saville-Troike, M. 2003. The ethnography of communication, an introduction. Blackwell.

[36] Taylor, R. et al. 2009. Exceptional students: Preparing teachers for the 21st century. McGraw-Hill.

[37] Temple, B. and Young, A. 2004. Qualitative research and translation dilemmas. Qualitative Research. 4, 2 (Aug. 2004), 161-178. DOI:https://doi.org/10.1177/1468794104044430.

[38] Traxler, C.B. 2000. The Stanford Achievement Test, 9th Edition: National Norming and Performance Standards for Deaf and Hard-of-Hearing Students. Journal of deaf studies and deaf education. 5, 4 (Jan. 2000), 337-348. DOI:https://doi.org/10.1093/deafed/5.4.337.

[39] vicdeaf 2010. Deaf culture \& communication: A basic guide. Victorian Deaf Society.

[40] Williams, C. 2004. Emergent literacy of deaf children. Journal of deaf studies and deaf education. 9, 4 (Jan. 2004), 352-365. 